\section{G19(P) GENETIC ANOMALIES IN INFANTS WITH CONGENITAL HEART DEFECTS: A RETROSPECTIVE OBSERVATIONAL ANALYSIS}

${ }^{1} \mathrm{~N}$ Thomas, ${ }^{1} \mathrm{R}$ Thompson, ${ }^{1,2} \mathrm{Y}$ Singh. ${ }^{1}$ School of Clinical Medicine, University of Cambridge, Cambridge, UK; ${ }^{2}$ Neonatology and Paediatric Cardiology, Cambridge University Hospitals NHS FT, Cambridge, UK

\subsection{6/archdischild-2020-rcpch.8}

Background and Aims Congenital heart defects (CHD) are the most common group of congenital malformation. With advanced testing - such as microarray and Next Generation Sequencing (NGS) - applied into routine clinical practice, more genetic anomalies may be detected in infants with CHDs.

Aims and Objectives The study was aimed to investigate the association between the congenital heart defects and genetic anomalies.

Methods A retrospective observational study included all the infants with a recoded new diagnosis of born CHD between 01/ 01/2017 and 31/12/2018, from a single tertiary neonatal intensive care unit. The data were recorded from the electronic patient records. For analytic purposes, CHDs cases were divided into 4 categories: critical, serious, significant or non-significant types.

Results 229 infants were identified, of which 8 were excluded due either to a lack of follow up or death from non-cardiac causes, which made classification impossible.

93\% of infants with critical CHD, and $85 \%$ of those with serious CHD, had relevant genetic testing, of which $31 \%$ and $41 \%$ had positive diagnoses, respectively. Significantly more infants with critical or serious CHD underwent relevant genetic testing than the infants with significant $(50 \%)$ or nonsignificant (12\%) CHD (p-value <0.01).

$\begin{aligned} & \text { Abstract G19(P) Table } 1 \\
& \text { within the patient cohort and number of associated genetic tests }\end{aligned}$
\begin{tabular}{llll} 
Classification & $\begin{array}{l}\text { Number of } \\
\text { Infants }\end{array}$ & $\begin{array}{l}\text { Number of Infants who had } \\
\text { Genetic Testing }\end{array}$ & $\begin{array}{l}\text { Positive Genetic } \\
\text { Test (\%) }\end{array}$ \\
\hline Critical & 14 & 13 & 31 \\
Serious & 26 & 22 & 41 \\
Significant & 38 & 19 & 58 \\
Non-Significant & 143 & 17 & 35 \\
Total & 221 & 71 & 42
\end{tabular}

Of the 24 infants with critical, serious or significant CHD diagnosed with a CHD related genetic anomaly: 8 were diagnosed with Trisomy 21; 3 with Noonan's syndrome; 1 with DiGeorge and the remainder with various microdeletions, microdeletions and single nucleotide variants.

Conclusions In our cohort, around one-third of the infants with critical and serious heart conditions had underlying genetic defects. The infants with critical and serious heart condition needing surgery or intervention within one year after birth are often tested for the underlying genetic defect. The uptake of genetic testing was far less in infants with significant or minor CHDs.

\section{G20(P) CARDIAC SCREENING IN CHILDREN PLANNED FOR STIMULANT MEDICATIONS: IS IT NECESSARY?}

S Banerjee, A Ahmed, B Sarder, P Nair. Paediatric Department, Bedford Hospital NHS Trust, Bedford, UK

10.1136/archdischild-2020-rcpch.9
Introduction ADHD (Attention Deficit Hyperactivity Disorder) affects $5-8 \%$ of children and adolescents. Stimulant medications have been proven to be an effective management strategy in many of these children. Children being considered for commencement of these stimulants are sometimes referred for cardiac screening to predict and prevent sudden death. NICE (National Institute of Clinical Excellence) has a set of criteria when cardiac screening is advised prior to commencement of treatment. However there is not much scientific data to suggest an increased risk in these children with use of stimulant medications.

Aim To look at the appropriateness of referral, investigations and outcomes of children referred to the PEC (Paediatrician with cardiac expertise) clinic for cardiac screening prior to commencement of ADHD medications.

Methods Retrospective analysis of referrals and consultation outcomes from Jan 2018 to Jan 2019.

Results 17 cases were referred by the community paediatricians to the PEC clinic. Of these 17 cases, 16 were boys and 1 was a girl. The age range was between 7-15 years with the average age being 11 years.

6 of the 17 cases were inappropriate and were not complying to NICE criteria, with the main reason being second degree relative having history of sudden deaths or pacemaker. The rest of the 11 cases were appropriate with the reasons being note of murmur, chest pains, palpitations \& history of sudden death in 1st degree relative.

All 17 patients had ECGs (Electrocardiogram) and echocardiography which were all reported as normal. 5 patients also had ambulatory ECG monitoring which were also normal. All 17 patients were discharged from the clinic with no cardiac contraindications found for start of stimulant medications.

Discussion Our study found that many of these referrals are inappropriate. Cardiac screening tests were normal in all patients. Many of these patients waited between 3 to 6 months to be screened in these clinics. The conclusion from this study is that delaying ADHD medications in these children is not warranted as there is substantial evidence regarding the safety and efficacy of these medications.

\section{G21(P) EBSTEIN'S ANOMALY IN THE NEONATAL PERIOD IS ASSOCIATED WITH VERY POOR PROGNOSIS - A 10 YEAR EXPERIENCE}

${ }^{1} \mathrm{M}$ Jagga, ${ }^{1} \mathrm{I}$ Nijjar, ${ }^{2} \mathrm{~T}$ Desai, 'SV Rasiah. ${ }^{1}$ Neonatal Intensive Care Unit, Birmingham Women's and Children's NHS FT, Birmingham, UKi ${ }^{2}$ Paediatric Cardiology, Birmingham Women's and Children's NHS FT, Birmingham, UK

\subsection{6/archdischild-2020-rcpch.10}

Introduction Ebstein's anomaly is a rare form of congenital heart disease (CHD), occurring in less than $1 \%$ of patients with CHD. With advances in Fetal Medicine and Cardiology, Ebstein's anomaly is being diagnosed antenatally. The literature highlights that it can be difficult to predict the prognosis particularly during the neonatal period.

Aims Our aim was to review the neonatal outcomes of babies with Ebstein's anomaly admitted to our tertiary neonatal intensive care unit (NICU).

Method We retrospectively identified all babies admitted to the NICU with a documented diagnosis of Ebstein's anomaly between 01/04/2009 and 31/04/2019. Their outcome data was collected using electronic patient records (BadgerNet). 